\title{
Calculating Expected Time of Delivery in Laboring Women Using Paperless Partogram: An Innovation for a Resource- limited Nation
}

\author{
Aloke Debdas ${ }^{1}$, Jayeeta R Mitra ${ }^{2}$, Ritesh Singh ${ }^{3}$
}

\begin{abstract}
Introduction: Partogram is an important tool to monitor the progress of labor. Existing WHO partogram is too cumbersome for the busy healthcare providers working in labor rooms in developing nations. There is a need to develop a more user-friendly way to measure the progress of labor and thus prevent the unfortunate events during labor.

Methods: The descriptive study was conducted in the Department of Obstetrics and Gynaecology of a teaching medical institution of India. The participants were patients in labor. Patients were enrolled once they fulfilled eligibility criteria and gave informed consent. Expected time of delivery (ETD) was calculated by application of Friedman's formula of cervical dilatation in "active phase" of labor of $1 \mathrm{~cm} /$ hour, which is applicable from $4 \mathrm{~cm}$ dilatation onwards. It was written in bold letters on the case sheet. Women were managed as usual, and the progress of labor was monitored. Proportion of women delivered within reasonable time of the ETD was calculated.

Results: Out of the 110 women included in the study, 73 (66.4\%) were nulliparous. The mean (SD) gestational age of them was 38.47 (1.4) weeks. More than half of the women presented at $4 \mathrm{~cm}$ cervical dilatation. $11.7 \%$ of the women required either 2.5 or $5 \mathrm{U}$ of Syntocinon injection. 75 (68.2\%) women delivered on or before time of the calculated ETD. 33 (30\%) women delivered within \pm 60 minutes of the calculated ETD. There was no significant association between the parity status of the woman and the induction of the labor. Similarly, parity status had no association with the time difference between the actual and expected time of delivery.

Conclusion: Paperless partogram is an important alternative to the conventional partogram. It can be used in resource-constraint settings to save resources and future mothers.

Keywords: Expected time of delivery, Obstructed labor, Paperless partogram, Partogram.

Journal of South Asian Federation of Obstetrics and Gynaecology (2020): 10.5005/jp-journals-10006-1837
\end{abstract}

\section{INTRODUCTION}

Obstructed labor causes approximately $8 \%$ of maternal deaths and indirectly contributes to a greater percentage of deaths in pregnant women. ${ }^{1}$ The techniques that help reduce mortality from obstructed labor include external cephalic version, contraception, the partogram, augmentation of labor, selective episiotomy, selective amniotomy, vacuum extraction, cesarean section, symphysiotomy in viable fetuses, and destructive procedures for nonviable fetuses. ${ }^{2}$ Other theories of doubtful practical use for preventing deaths while in labor include maternal height and shoe size, vaginal cleansing, upright posture for delivery, and vaginal lubrication. There still exist unproven and sometimes harmful techniques to prevent mortalities associated with obstructed labor and they include interventions based on pelvimetry, estimation of fetal weight, early labor induction, routine amniotomy, routine augmentation, routine episiotomy, and starvation during labor.

In resource-poor countries, there are problems of paucity of skilled labor, increased delivery load, lack of basic amenities for fetal monitoring like cardiotocography (CTG), and measurement of fetal scalp blood $\mathrm{pH}^{3,4}$ The obstetricians in a developing and less developed nation have to encounter challenging labors all the time. Many a time, the busy obstetrician and midwives get exhausted due to sheer number of mothers to be taken care of, which may lead to error in judgment and ultimately unintentional clinical catastrophes. Thus, it has become imperative to devise a method that would help organize the dwindling workforce and amenities accordingly so that serious patients may be identified, managed,

\footnotetext{
${ }^{1}$ Department of OBG, MGM Medical College, Jamshedpur, Jharkhand, India

${ }^{2}$ Department of OBG, IQ City Medical College, Durgapur, West Bengal, India

${ }^{3}$ Department of Community and Family Medicine, AllMS Kalyani, West Bengal, India
}

Corresponding Author: Ritesh Singh, Department of Community and Family Medicine, AllMS Kalyani, West Bengal, India, Phone: +91 9836444242, e-mail: drriteshsingh@yahoo.com

How to cite this article: Debdas A, Mitra JR, Singh R. Calculating Expected Time of Delivery in Laboring Women Using Paperless Partogram: An Innovation for a Resource-limited Nation. J South Asian Feder Obst Gynae 2020;12(6):363-365.

Source of support: Nil

Conflict of interest: None

and not overlooked in a busy and crowded labor room. Tweaking the existing partogram is one way of handling the situation. ${ }^{5}$ Most of the obstetricians and midwives agree that meticulous plotting of the process of labor in a graphical form-into the standard partogram graph-needs more time and manpower to monitor and note the data into the graph. The learning curve of using and implementing the existing partogram is a slow one-needing time and motivation that an inadequately staffed busy labor room is unable to provide. ${ }^{6,7}$ Keeping these practicalities in consideration, the lead researcher of the paper has devised a system of paperless 
partogram by using an easy calculation for estimating the expected time of delivery (ETD) so that majority of mothers benefit by getting the timely care from the vital skilled workforce. The objective of the current study is to find out whether ETD can be used as an effective tool to prevent "time-related" serious immediate and late complications like prolonged labor, obstructed labor, obstetric fistulae, and major perinatal problems of labor.

\section{Methods}

This descriptive study was conducted in the Department of Obstetrics and Gynaecology of a teaching medical institution located in the state of West Bengal in India. The participants were patients in labor. The criteria to be included in the study were uncomplicated pregnancy of gestational weeks 37 or more, the contractions should be at least 1 in 10-minute intervals, cervical os should be at least $4 \mathrm{~cm}$ dilated, cephalic presentation, and vaginal delivery. The membranes may be intact or ruptured. The study was conducted for a year from 2014 to 2015. The exclusion criteria were induced or augmented labor, multiple pregnancy, past history of thromboembolic disease, fetal distress, severe medical illness complicating pregnancy necessitating early delivery, malpresentation, and women with previous cesarean section.

\section{Calculation of Two "Expected Time of Delivery" (ETD)}

The two ETDs that were calculated were the "Alert ETD" and the "Action ETD." It takes just "split of a second" to do so and is a "one time" mental job. These were then written down in the front page of the case sheet in big bold letters. The calculation was done by application of Friedman's formula of cervical dilatation in "active phase" of labor of $1 \mathrm{~cm} /$ hour, which is applicable from $4 \mathrm{~cm}$ dilatation onward. ${ }^{8}$ For instance, if a patient had come at 2 p.m. and her per vaginal (PV) examination revealed that her dilatation at that point of time was $4 \mathrm{~cm}$, then her first ETD, i.e., the "Alert ETD," was 2 p.m. +6 hours ( 6 hours was for the remaining $6 \mathrm{~cm}$ that her cervical os had to dilate to become $10 \mathrm{~cm}$ at the rate of $1 \mathrm{~cm} /$ hour) 8 p.m. The other ETD or the final ETD or the "Action ETD" was derived adding 4 hours to the Alert ETD, i.e., 8 p.m. +4 hours or at 12 midnight. This final time figure was written in red to make it more prominent. Alert ETD denotes the time when the mother in labor is expected to deliver normally vaginally in the normal course without augmentation. It acts as a red flag, if the mother has not done so the caregiver should get alerted and review the case critically. Action ETD is the decision time. This time is very vital, and if the mother has not delivered spontaneously even by the end of this intensely monitored extra time, action should be taken to deliver her reasonably soon by the suitable means. The purpose of writing these important time figures in big bold letters is that everyone concerned (both nurses and doctors) compulsorily notice it, remain acutely and constantly aware about it, and manage labor so as to deliver her by these two time stages or targets. The entire process of calculating two ETDs and writing on case sheet takes less than 20 seconds of a clinician's time. As can be seen, by this simple 20-second action, the caregiver precisely knows where and how labor should be terminated. In other words, the labor gets programmed. We can thus prevent the occurrence of prolonged and obstructed labor, which is the root cause of most maternal, fetal, and neonatal morbidity and mortality. The patients were managed as done in any case of labor. The primary outcomes studied in the research were validity of ETD (number of women delivering vaginally at \pm 30 minutes and at \pm 60 minutes), incidence of normal vaginal delivery, and incidence of instrumental vaginal delivery. The secondary objectives were incidence of birth asphyxia, incidence of obstructed labor, and maternal morbidity. The results for each parameter for discrete data and averages for continuous data are presented in tables. The proportions were compared using chi-square test of significance. The Student's $t$ test was used to determine whether there was a statistical difference between two groups in the parameters measured. In all the above tests, the $p$ value of 0.05 or less was accepted as indicating statistical significance. Data analysis was carried out using Statistical Package for Social Science (IBM SPSS ${ }^{\circledR}$ V 22.0) package.

\section{Result}

There were 110 women in labor included in the study. 73 (66.4\%) of them were nulliparous. The mean (SD) age of them was 23.30 (3.4) years (Table 1). The mean (SD) gestational age of them was 38.47 (1.4) weeks. More than half (51.8\%) of the women presented at $4 \mathrm{~cm}$ cervical dilatation. The os was $\geq 8 \mathrm{~cm}$ dilated for $13.7 \%$ of women at the time of presentation in the labor room. $13(11.7 \%)$ of the women required either 2.5 or $5 \mathrm{U}$ of oxytocin injection for induction. For only one woman, emergency lower uterine cesarean section (LUCS) was done. $63.3 \%$ of the women required at least a dose of analgesic. 57 (51.8\%) girls were born. The mean (SD) birth weight of newborn was $2.7(0.4) \mathrm{kg} .75$ (68.2\%) women delivered on or before time of the calculated ETD. The mean (SD) of the difference in time between the calculated and actual ETD in these 75 women who delivered before the calculated ETD was 2 hours 10 minutes (1 hour 25 minutes). 35 (33.6\%) women delivered after time of the calculated ETD. The mean (SD) of the difference in time between the calculated and actual ETD in these 35 women who delivered after the calculated ETD was 2 hours 22 minutes ( 2 hours 9 minutes). 33 (30\%) women delivered \pm 60 minutes of the calculated ETD. $66 \%$ of the primigravida delivered before ETD, whereas $73 \%$ of the multigravida delivered before the ETD, though there was no significant difference between these two groups. Though more percentage of multigravida women delivered spontaneously, there was no significant association between the parity status of the woman and the induction of the labor (Table 2). More multigravida

Table 1: Baseline characteristics of the mothers

\begin{tabular}{llll}
\hline Variable & Range & Mean & $\begin{array}{l}\text { Standard } \\
\text { deviation }\end{array}$ \\
\hline $\begin{array}{l}\text { Age (in years) } \\
\begin{array}{l}\text { Gestational age } \\
\text { (weeks) }\end{array}\end{array}$ & $19-35-41$ & 23.30 & 3.4 \\
$\begin{array}{l}\text { Weight of the } \\
\text { child (kg) }\end{array}$ & $2.00-3.80$ & 38.47 & 1.43 \\
$\begin{array}{l}\text { Time difference } \\
\text { between actual } \\
\text { and expected } \\
\text { delivery time }\end{array}$ & $\begin{array}{l}5 \text { hours 55 minutes } \\
\text { before ETD-7 hours }\end{array}$ & -43.1 minutes & 2 hours \\
\hline
\end{tabular}

Table 2: Distribution of study participants according to mode of delivery*

\begin{tabular}{lccc}
\hline Type of delivery & Primigravida & Multigravida & \multicolumn{1}{l}{ Total } \\
\hline Spontaneous & $64(87.7 \%)$ & $33(89.2 \%)$ & $97(88.2 \%)$ \\
Induced & $9(12.3 \%)$ & $4(10.8 \%)$ & $13(11.8 \%)$ \\
Total & $73(100 \%)$ & $37(100 \%)$ & $110(100 \%)$ \\
\hline
\end{tabular}

${ }^{*}$ Column percentage, $p$ value $>0.05$ 
Table 3: Actual time of delivery with respect to expected time of delivery in participants*

\begin{tabular}{lllr}
\hline Actual time of delivery & Primigravida & Multigravida & Total \\
\hline Before ETD & $48(65.8 \%)$ & $27(73 \%)$ & $75(68.2 \%)$ \\
After ETD & $25(34.2 \%)$ & $10(27 \%)$ & $35(11.8 \%)$ \\
Total & $73(100 \%)$ & $37(100 \%)$ & $110(100 \%)$ \\
\hline
\end{tabular}

${ }^{*}$ Column percentage, $p$ value $>0.05$

Table 4: Time difference between actual and expected time of delivery (minutes) in study participants*

\begin{tabular}{lll}
\hline Time difference & Primigravida & Multigravida \\
\hline $\begin{array}{l}\text { Time difference between actual and } \\
\text { expected time of delivery (minutes) }\end{array}$ & -25.6 & -77.6 \\
\hline$p$ value $>0.05$ & &
\end{tabular}

women delivered before the expected time of delivery (Table 3). Similarly, parity status has no association with the time difference between the actual and expected time of delivery (Table 4).

\section{Discussion}

The partogram is an important tool that helps obstetricians and midwives to record maternal and fetal conditions pictorially. ${ }^{9}$ There have been many variants of the partogram. Cartmill et al. ${ }^{10}$ stated that a partogram affects a midwife's or obstetrician's perception of the labor progress and thus influences the decision-making. We believe that the traditional partogram is time-consuming for overburdened clinicians and also complicated for many skilled birth attendants. The "paperless partogram" as proposed by us is a low-skill method for preventing obstructed labor, and has been shown to be associated either directly or indirectly for decreasing maternal morbidity and mortality. Developing and poor nations do not have necessary facilities where traditional partogram can be effectively used. In the present study, we have used the paperless partogram for the management of labor. Out of 110 participants, labor was induced only in $11.8 \%$ of the cases. This figure is lower than in a study of an uncomplicated primigravida population, which used the WHO partogram. ${ }^{11}$ The percentage of women requiring induction of labor is similar as noted by Agarwal et al. ${ }^{12}$ who used the same "paperless partogram." The difference in time between the actual and expected time of delivery was -25.6 minutes in primigravida and -77.6 minutes in multigravida women; however, these differences were not statistically significant. The cesarean delivery rate was $1 \%$ in our study. As we studied only a small number of women in labor over a short period of time, we recommend doing a larger study to see the uses of paperless partogram more critically. As partograph is utilized mainly in tertiary health facilities and knowledge about partograph among peripheral workers is poor, further research in this field and training of personnel are mandatory. This paperless partogram is very simple to understand and can be implemented even in rural setup and by midwives with minimal training. The appropriate time of referral needs more emphasis on continuing education, and partograph should be promoted for use by midwives and MBBS doctors who care for laboring women in primary healthcare centers. The advantages of "paperless partogram" are that no separate paper or special training is required. It is very user-friendly and takes less than 20 seconds of time to calculate and write down on case sheet important timings.

\section{ACKnOWLedgments}

The research was cleared by the Institutional Ethics Committee of the College of Medicine and JNM Hospital, WBUHS, Kalyani. Informed consent was taken from each participant before the study. There is no conflict of interest. AD and JRM collected the data. RS designed the study and helped in writing the first draft. All authors have agreed to get the research published.

\section{References}

1. Nour NM. An introduction to maternal mortality. Rev Obstet Gynecol 2008 Spring;1(2):77-81.

2. Hofmeyr GJ. Obstructed labor: using better technologies to reduce mortality. Int J Gynaecol Obstet. 2004;85(Suppl. 1):S62-S72. DOI: 10.1016/j.ijgo.2004.01.011.

3. Bajwa SK, Bajwa SJS. Delivering obstetrical critical care in developing nations. Int J Crit IIIn Inj Sci 2012;2(1):32-39. DOI: 10.4103/22295151.94897.

4. Omo-Aghoja L. Maternal and fetal acid-base chemistry: a major determinant of perinatal outcome. Ann Med Health Sci Res 2014 Jan-Feb;4(1):8-17. DOI: 10.4103/2141-9248.126602.

5. Ollerhead E, Osrin D. Barriers to and incentives for achieving partograph use in obstetric practice in low- and middle-income countries: a systematic review. BMC Pregnancy Childbirth 2014;14:281. DOI: 10.1186/1471-2393-14-281.

6. Mathibe-Neke JM, Lebeko FL, Motupa B. The partograph: a labour management tool or a midwifery record? Int J Nurs Midwifery 2013;5(8):145-153. DOI: 10.5897/IJNM2013.0115.

7. Bulatao RA, Ross JA. Rating maternal and neonatal health services in developing countries. Bull World Health Organ 2002;80(9):721-727.

8. Philpott RH, Castle WM. Cervicographs in the management of labour in primigravidae. J Obstet Gynaecol Br Commonw 1972;79(7):592598. DOI: 10.1111/j.1471-0528.1972.tb14207.x.

9. Mathai M. The partograph for the prevention of obstructed labor. Clin Obstet Gynecol 2009;52(2):256-269. DOI: 10.1097/ GRF.0b013e3181a4f163.

10. Cartmill RS, Thornton JG. Effect of presentation of partogram on obstetric decision making. Lancet 1992;339(8808):1520-1522. DOI: 10.1016/0140-6736(92)91275-d.

11. Lavender T, Alfirevic Z, Walkinshaw S. Effect of different partogram action lines on birth outcomes: a randomized controlled trial. Obstet Gynecol 2006;108(2):295-302. DOI: 10.1097/01. AOG.0000226862.78768.5c.

12. Agarwal K, Agarwal L, Agrawal VK, et al. Evaluation of paperless partogram as a bedside tool in the management of labor. J Family Med Prim Care 2013;2(1):47-49. DOI: 10.4103/2249-4863.109944. 